\title{
Our Moral Duty to Eat Meat
}

\begin{abstract}
I argue that eating meat is morally good and our duty when it is part of a practice that has benefited animals. The existence of domesticated animals depends on the practice of eating them, and the meat-eating practice benefits animals of that kind if they have good lives. The argument is not consequentialist but historical, and it does not apply to nondomesticated animals. I refine the argument and consider objections.
\end{abstract}

KEYWORDS: animals, carnivorism, vegetarianism, veganism, benefit, duty, meat

Eating nonhuman animal meat is not merely permissible but also good. It is what we ought to do, and it is our moral duty. So I argue. I shall not distinguish the claim that eating meat is good from the claim that we ought to eat meat. The claim that it is our duty is a stronger claim. The claim that it is good and the claim that it is what we ought to do are closely related to the claim that it is our duty: if something is our duty, then it is good to do it, and we ought to do it. Furthermore, I take the goods, oughts, and duties here to be moral ones. Note also that by the word 'animals' in what follows, I mean nonhuman animals, and by 'meat' I mean nonhuman animal meat.

\section{The Benefit to Animals of Eating Meat}

Why is eating meat good? That is, what makes it good? The basic claim, to put it crudely at first, is that eating meat is morally good primarily because it benefits animals. Of course, the practice does not benefit a particular animal that we eat at the time that we eat it. Nevertheless, the existence of that animal and animals of that kind depends on human beings eating animals of its kind and, hence, that meat-eating practice benefits them. Domesticated animals exist in the numbers that they do only if there is a practice of eating them. For example, the many millions of sheep in New Zealand would not begin to survive in the wild. They exist only because we have a practice of eating them. The meat-eating practice benefits them greatly. Therefore, we should eat them.

The argument, to be more precise, is that we should eat meat where meat-eating is part of a past and ongoing practice that benefits animals. The animals we eat should have good lives, and their pleasures and happiness are part of that. It is an empirical question how much of actual current meat-eating fits this description. It may be that

I am grateful for helpful and challenging comments from a referee and also for comments from Julia Driver, Simon James, Suzi Killmister, and Rebecca Tuvel, none of whom agree with my conclusions. This paper had its origins in a talk prepared for a number of student philosophy societies. Many thanks for questions from those in these audiences. 
only animals reared in decent ways have good lives, and that so-called factory-farmed animals have little or no quality of life, or that their pain outweighs their pleasure. If so, the argument from benefit to animals does not apply to factory farm animals. Perhaps we should not eat factory-farmed animals. Nevertheless, very many animals we eat do not live dismal lives, and the argument clearly applies to them. For example, the millions of sheep in New Zealand that graze outdoors overall have good lives. Therefore, we should eat them. A great deal of meat is not factory farmed, and is, as it were, fair game. The argument does not justify participating in practices where there is no quality in animals' lives. However, it is not seriously questionable that much meat-eating of the more 'free-range' kind of animals does enable a significant quality of life for the animals in question. It is hard to get reliable and impartial information about how much of each kind there is, but it seems that at least around 5 percent of actual meat production is of the more benign sort. That justifies an awful lot of meat-eating. When I speak of eating meat being justified in what follows, I shall mean only meat from animals that overall have a good life. A minority of meat produced in the world today involves such happy animals. But it is a significant minority, one that justifies much eating of those animals.

It is a relatively uncontroversial empirical premise that if the market for meat dried up, farmers would stop caring for animals and breeding them (Scruton 2000). Of course, if human beings were radically different-perhaps if they were immaterial or immortal or could draw nutrition from the air-then our obligations to animals would be different. But so what? We are dealing with our world or a world like our world. Of course, there are various barely possible utopian visions or fantasies in which large numbers of animals somehow get cared for without being killed and eaten. However, given the world as it is, the only way for animals to benefit in large numbers is to kill and eat them. Therefore, we should kill and eat them.

\section{Consciousness, Happiness, Suffering, and Death}

It seems to be obvious and intuitive that benefitting animals is good. But what if the question is asked: why, exactly, is it good to benefit animals? What is the ground of the obligation to benefit animals, whether individual animals or animals of a kind? We can also benefit bacteria. But we do not think that this something we should do. Why not?

On this point, I agree with those, such as Peter Singer (Singer I975), who think that what is important is animal consciousness. They think that animal consciousness means we ought not to eat animals, whereas I think the very opposite. Nevertheless, we can agree that the ground of our obligations concerning animals is consciousness-there is something it is like to be many animals-which is why those animals have interests that matter morally: the quality of their consciousness can be better or worse. By contrast, bacteria have interests; they can be benefitted or harmed, and they can flourish or not. However, there is nothing it is like to be bacteria; they are not conscious. It is also unlikely that there is something it is like to be an earthworm. Therefore, we do not have obligations to bacteria and earthworms, or at least not this kind of obligation. 
Because some animals are conscious, they have interests and can flourish in a way that matters morally. But for many kinds of animals (cows, sheep, chickens), in order to exist and flourish in that way there must be a practice of eating them. Therefore, we should eat them.

I do not deny that animal pain and suffering matter. However, we should insist, and strongly so, that animal pleasure and happiness also matter-something almost entirely overlooked by huge numbers of those who write with apparent concern for animals. The emphasis among the defenders of so-called animal liberation or animal rights on animal pain and suffering rather than on animal pleasure and happiness is bizarre and disturbing (for example, Singer 1975; Regan 1983). The only explanation I can think of is that this emphasis is a form of what is called speciesism: animal pleasure and happiness are discounted just because they are not of our species. There is an impressive inconsistency in this because those who present themselves as having great concern for animals somehow omit to factor in the benefit to animals of pleasure and happiness. This looks like speciesism because they think human pleasure and happiness matters, while they do think the same of animal pleasure and happiness, and they care only about animal pain and suffering.

It is imperative that moral issues about suffering and death are separated. There are moral issues about the suffering and happiness of animals, and there are moral issues about whether we can or should kill animals. These issues are clearly separate in principle. Killing could ideally be completely painless and free of suffering. Of course, the fact that animals feel pain and pleasure is relevant to how we should care for them and nurture their interests during their lives, and it is also relevant to how we should kill them. But that fact is not in itself relevant to whether we may kill animals for food if their death is painless. These two issues are often confused. In fact, killing animals and eating them is not merely compatible with kindness and benefit to animals but is required if we are to be kind to animals and to benefit them. Otherwise there would be no such animals to be kind to or to benefit. The goal of kindness to animals dictates that we should kill and eat them.

The ideal of painless death may not be achieved in many cases. The animals we eat may incur some pain or suffering at the end of their lives, which is regrettable. Nevertheless, it is vastly less than the overall good in their lives. Therefore, even if they feel pain or suffering at the end, it is not remotely plausible that pain and suffering at the end of their lives somehow negates all the good in their lives that they had before that. That would be a strange fetishization of their last few moments. It is also true that many human beings have miserable painful deaths, but that hardly means that their lives before that were not worth living. Nevertheless, we should certainly strive to minimize animals' pain and suffering in the process of killing them.

Some people think that how life ends matters for human beings in a way that it does not matter for animals. If this is true, it is presumably due to our cognitive sophistication, which allows us to conceive of our life as having something like a narrative structure. But without that cognitive sophistication, the end of life cannot carry the special weight it does for many people who argue that we should not eat animals. Because animals lack the cognitive sophistication of human beings, no special weight can attach to their last moments when considered in the light of their lives as a totality. 
Like human beings, animals have pains and miseries, but like human beings, a great many of the animals we eat also have considerably more pleasure and happiness in their lives than pain and misery. Therefore, we should eat them.

\section{Three Comments}

(A) In the course of arguing that coming into existence is always (but not necessarily) a harm for human beings, David Benetar argues for an asymmetry between pleasure and suffering (Benetar 2006: 30-36). He thinks that the absence of pleasure is not bad, whereas the absence of pain is good rather than just not bad. Benetar claims that this is because absent pleasure must belong to some specific existing person if it is to be regrettable, whereas this is not true of absent pain. Let us concede for the sake of argument that Benetar has located an asymmetry here between pleasure and pain. Even so, that does not make it plausible that the absence of pain is a positive good rather than being neutral. Of course, conscious life without pain may be good. In that case, lacking pain enables good things, which might confuse us into thinking that lacking pain is itself good. But it is not good in itself. The number 7 also lacks pain, but there is nothing good about the number 7 lacking pain. The mere absence of pain is not itself good although in a living being that is conscious, it enables good. What is in question is the value of a life, an animal's life considered as a totality; and there is no reason to think that this value is constituted only by negatives, such as pains, and not at all by positives, such as pleasures.

(B) A complication is that different animals have different degrees of consciousness. Different animals also have different kinds of consciousness. Consciousness varies in vividness, fine-grainedness, and so on. It is plausible that we have greater obligations to advance the interests of animals further up the hierarchy of consciousness. This means that we should concentrate our efforts on breeding, killing, and eating animals with higher levels of consciousness if those lives are good overall. Suppose there were evidence that an animal, such as a sheep, feels more pleasure and distress than does a chicken. Then we would have greater duties to sheep than to chickens. And if so, other things being equal, given a choice between lamb and chicken, we should eat lamb and not chicken. (In fact, there is evidence of the considerable 'cognitive' sophistication of chickens (see Marino 20I7). But, first, it is not clear whether or not that sophistication spills over into their consciousness, and second, it does not affect the point of principle concerning hierarchies of consciousness.)

(C) What about the argument that calves and their mothers incur psychological suffering when they are separated in the process of meat production? I already conceded that there is suffering in the lives and deaths of domesticated animals, but I downplayed its importance in the overall balance of things. The worry is that we cannot do this so easily with the more sophisticated emotional suffering of animals like cows, where significant attachments develop. Nevertheless, the important question remains: is the cow's life as a whole good? There is no reason to believe that the sophisticated trauma of separation in the life of a cow makes a cow's whole life not worth living, any more than the many traumas in the lives of 
human beings make their lives not worth living. Indeed, quite the opposite: human grief is proof that human life is worth living, despite the trauma of loss. Grief is an eloquent testament to the value of life. The same goes for the cow's separation trauma. The argument runs exactly the other way from the way it is assumed to run. If cows can grieve or suffer separation trauma, that is proof of the sophistication and high quality of the cow's mental life, which provides all the more reason to eat cows as part of a practice whereby they benefit. Of course, the grief of animals matters, and it should be factored into our assessment of the value of their lives; the fact that they feel grief makes a difference to our behavior with respect to animals via the practices that sustain or have sustained the quality of life for those animals. However, animal grief speaks in favor of eating animals, not against it.

\section{Beneficial Historical Practices: Wild and Domesticated Animals}

The above is half of the positive argument: the appeal to the benefit to animals and the appeal to consciousness. What needs to be added is the fact that our relationship with domesticated animals, by contrast with wild animals, makes a significant moral difference.

We are in ongoing symbiotic relationships with many types of animals (such as cows, sheep, and chickens), and there are long-standing practices whereby we benefit them and they benefit us. It is as if we were in a relationship of friendship with them-and that is why we should eat them! We have duties to benefit our friends in virtue of our special relationship with them; benefitting them is not merely virtuous or praiseworthy (Zangwill 20II, 20I8). Likewise, in virtue of the ongoing mutual dependency of animals on us and of us on them, it is our duty to eat them, and this is not something merely virtuous or praiseworthy. If there turn out to be creatures on Mars that would be benefitted by our eating them, then it would be virtuous or praiseworthy to eat them, not our duty. We actually stand in an ongoing relationship of mutual dependence with many earthly species, and thus eating them is not merely virtuous or praiseworthy-we have a duty to eat them, just as we have special duties to our friends. It is true that it is not usual to eat our friends, and so, in this respect, the two situations are indeed different. I concede that. But the situations are similar in that duties arise in the context of a relationship of mutual dependence.

This marks a significant difference between domesticated and wild animals. Consider the billions of nondomesticated animals in the wild who kill and eat each other. These animals have pleasures and pains; does that mean that we also have obligations to them? Should we intervene to prevent the lion from eating the gazelle? But this aspect of these animals' lives is an unalterable part of nature ('Nature red in tooth and claw'). This is not true of domesticated animals that are mostly spared the fear of predators, thanks to human beings.

The fate of wild animals is not entirely disconnected from us. The actions of human beings affect them. That is not the issue here-the issue is the lack of a mutually beneficial symbiotic relationship with them. Because of that, we are not obligated to interfere with the endless cycle of life and death in the wild. Indeed, 
we should probably not interfere unless it is to undo previous wrongful intervention (Schmidz 2008). By contrast, it is our duty to eat the animals we have domesticated because we are in an ongoing relationship of mutual dependence with those domesticated animals. Furthermore, it is a relationship that benefits the domesticated animals. In virtue of their ongoing consciousness and its quality, the lives of many domesticated animals are good. But that good depends on our eating them. This is not true of the conscious lives of wild animals. Therefore, we have a duty to eat domesticated farm animals but not wild animals.

Suppose that due to some disease the animals we have cared for and caused to exist would have no descendants. For example, there would be no more sheep in the future. Then we may still eat the last generation of sheep in virtue of their participation in a practice that has benefitted those sheep and many of their forbears. Must we eat them? Perhaps not in that situation although we may do so.

Carnivorism has been immensely beneficial to its practitioners, both human beings and the animals they eat. If there are present duties to continue the practice, the practice must have been beneficial: Chinese foot-binding was a long-standing cultural practice but not a beneficial one; thus, that history confers no present duty to persist. But carnivorism is and has been highly beneficial to both the eater and the eaten. Therefore, that practice generates duties.

There is a question about the identity conditions of carnivorous practices. The animals we eat should be of the same kind as the animals that were benefitted by that practice in the past: a practice that benefits chickens cannot justify us in eating ducks. If a carnivorous practice benefits chickens but not ducks, then that practice generates duties to eat chickens and not ducks. It would be unfair to chickens to eat ducks instead of chickens.

Do we have a duty to breed huge numbers of animals to feel pleasure and happiness? No, the argument is not a consequentialist one. We have a duty to be the gentle custodians of happy animals that we eat because of our ongoing beneficial relationship of mutual dependence. Perhaps larger herds or flocks of domesticated animals are better than smaller ones. But there is no requirement to maximize. The best way to do our duty, given what the world is like, is probably to continue a tradition of breeding, tending, and eating animals that have lives that are good overall. New Zealand famously has ten sheep for every person. Right now, the people of New Zealand are pursuing a morally righteous policy, which must be almost optimal given the limits imposed by facts about human beings, society, and economics. New Zealand farmers may or may not be motivated by the cause of animal welfare. Irrespective of their motivations, they have contributed and are contributing very substantially to the cause of animal welfare, which is what matters. New Zealand sheep farming is a noble practice, and New Zealand sheep farmers are heroic benefactors of animal kind.

The ongoing history of mutual benefit is the ground of the present moral duty of human beings to eat animals. If the practice were beneficial only to one of the two parties, that would perhaps not justify persisting in it. But both parties benefitand animals benefit a lot more than human beings. For human beings could survive as vegetarians or vegans, but domesticated animals could not survive human beings being vegetarians or vegans. Indeed, if most human beings became 
vegetarians or vegans, it would be the greatest disaster ever for animal kind since an asteroid strike precipitated an ice age that wiped out the dinosaurs and many other species.

\section{Other Writers: Compare and Contrast}

Some writers have discussed the appeal to benefit to animals, and considering their views will help clarify some issues and locate my view more exactly. In particular, considering these other views will allow me to highlight the specifically historical nature of my appeal to animal benefit.

The writer nearest to my own views that I have found is Baird Callicott: in a recent essay, he defends what he calls a 'communitarian' account that vindicates meat eating in a mixed 'biotic' community of human beings and domesticated animals (Callicott 2016). He distinguishes the communitarian view from rights and consequentialist views in a way that seems correct, and he presents some well-aimed criticisms of those other views. He also thinks that there is an implicit social contract' between human beings and some domesticated animals that allows us to kill and eat those animals (Callicott 20I6: 57). Although these views seem broadly on the right track, I think that more needs to be said. While there are mutually beneficial practices in which human beings and animals participate, it is not clear that they amount to 'community' in the sense in which people may 'identify' with their families, ethnicities, religions, nations, and so on. In those cases, there are patterns of nested feelings and values that hold these communities together. But there need be no feelings or evaluations for there to be systematic mutual benefit, which is sufficient to generate duties in the case of human beings and domesticated animals. Moreover, it is not clear what a 'biotic' community would be. It would be very different from what communitarian moral and political thinkers have in mind when they appeal to of families, religions, ethnicities, and nations. It is true that these communities also generate practices of mutual benefit among the participants. But for the practices that $\mathrm{I}$ have in mind as the ground of carnivorism, it does not matter what human beings and animals think or feel, so long as there has been an ongoing stable, beneficial practice. Moreover, for Callicott, human beings are members of a 'biotic' community that includes plants as well as animals, which also generates obligations to these plants. However, according to the argument I am pursuing, the moral obligations to animals arise from their consciousness.

Singer cites Henry Salt who cites Leslie Stephen who remarked: 'The pig has a stronger interest than anyone in the demand for bacon' (Singer I979: II5; Stephen I 896). Singer then seems to endorse a similar view for some animals. Singer follows Michael Tooley in distinguishing animals that are self-conscious, that is, animals that have a conception of themselves and that have preferences concerning their own future, from conscious but non-self-conscious animals. According to Singer, we should not eat conscious but self-conscious animals even if it is to their general ('total') benefit. The particular identity of these animals matters; they are not replaceable by qualitatively similar self-conscious animals. Therefore, we cannot kill and eat some to benefit others. By contrast, for Singer, 
we can do this to non-self-conscious animals, which are replaceable by qualitatively similar non-self-conscious other animals. In order to maximize their total welfare, Singer allows that we can kill and eat some to benefit others, if the overall total welfare is more than it would be if we did not do so. Singer's hypothetical defense of carnivorism is surprising, given what we might think we know of his views: Singer thinks that we can and should kill and eat animals that lack a reflective self-conception so long as it maximizes their happiness; that means that we can kill and eat (well-cared-for) non-self-conscious chickens if that generates the best consequences when compared with alternatives. I have two comments on this: first, it is not clear how he can restrict the total good consequences to animals of the species in question rather than taking into account all non-self-conscious animal kind, whereas on my historical benefit view, the species restriction is built in because the practices are species-specific. Second, Singer's argument is a consequentialist argument; mine is not. Singer's consequentialism would in some cases entail that we should renege on what I think are our historically generated duties to a species, which hold in virtue of a past and ongoing mutually beneficial practice. But respecting that history may not coincide with what overall future consequences demand.

Is the view proposed here a version of the hypothetical social contract theory (Mackie I977)? Perhaps it is true that animals and human beings should, hypothetically, have contracted into the meat-eating practice given that both had much to gain. Human beings and animals would have been right to make such a contract because the practice would be mutually beneficial. That means that the hypothetical contract is not fundamental. Future consequences may have been relevant to the question of whether or not human beings and animals should, hypothetically, have initiated a practice in the past. But this is not the situation in which human beings find themselves now. While a past hypothetical contract might have been justified by what then lay in the future, on the view defended here, the present carnivorous practice is justified by the actual and nonhypothetical past history of mutual benefit.

Jeff McMahan (2008) considers and rejects what he calls 'benign carnivorism'. 'Benign carnivorism' is the consequentialist view that eating meat is good because it maximizes welfare for animals. In some respects, this is similar to the historical benefit view defended here, and in some respects it is not. McMahan objects that once an animal exists, how it got there is irrelevant history, even if it arose from an overall benign practice that benefits its brethren (McMahan 2008). But dispensing with history in this way is implausible. History is relevant-indeed crucial. Suppose that an animal miraculously could suddenly understand, reason, and speak for an hour before permanently losing those extraordinary temporary cognitive, rational, and linguistic capacities. And suppose it took the opportunity to protest at its life being cut short by being killed and eaten. We could argue in reply to the animal that if it pleads to be treated differently from other animals, it is a selfish free rider. It has been the beneficiary of a practice in which there is limited life with many positive qualities. The animal who would avoid its fate therefore undermines a practice that has benefitted it and that will continue to benefit many other animals. The animal is in a prisoner's dilemma. True, the dilemma is not one of its own 
making. Yet, consider the payoff structure for a particular animal. (A) That animal has an uncurtailed life while other animals have no life at all. (B) All animals have curtailed lives (compare Callicott 20I6: 57). Our miraculous animal that can temporarily understand, reason, and speak, ought to opt for cooperation-option (B). That would be the right thing to do. That is what it should do in the prisoner's dilemma in which it finds itself, just as human beings should pay taxes rather than avoid them, not cut across lawns, and act similarly in the countless other prisoner's dilemmas in which human beings find themselves. It would be unfair of the animal to escape it fate. This shows that it is not clear that McMahan can press the point that all that matters is what is good for the animal at the point at which its death is imminent. It surely matters how the animal got there. History matters. Such an argument overlooks the prisoner's dilemma structure of the animal's situation. The temporarily miraculously thinking, reasoning, and speaking animal should meekly resign itself to its fate because it is the beneficiary of a benign practice that it should not undermine. (I return to some of McMahan's other arguments below.)

\section{Killing and Eating Enslaved Human Beings?}

I have now laid out the main argument for eating animals-the argument from historical beneficial practice. Let us now consider four refinements and objections: first, the extension of the argument to human beings is dismissed; second, I ask which animals, exactly, have benefitted and of which animals does the duty hold; third, goodness and good-for are addressed; and fourth, I ask who, exactly, is bound by the obligation.

There is one counterargument that has not been addressed thus far, which is likely to have occurred to the reader. This is the argument that if the argument from historic benefit to animals were good, it would have the consequence that we should at least sometimes kill and eat enslaved human beings if doing so were part of a practice that has benefitted them. This counter-argument needs to be neutralized; otherwise it will fester unhealthily in the background and be a distraction from the main thrust of the argument for eating meat. Addressing this objection in full would involve us in the large issue of whether there is a moral line between human beings and animals, and whether human beings have special rights in virtue of their rationality. These rights would include, for example, that we cannot sacrifice one human being to save five other human beings. These are interesting and important issues, and they need to be pursued in depth. (I do so elsewhere in work in preparation.) But these issues are not relevant to the substance of the argument pursued here. Perhaps the historical benefit argument has certain consequences for eating human beings, and perhaps it does not; perhaps those consequences would be acceptable and perhaps not. However, even if the argument does have those consequences, it does not affect the question of whether the argument from historical and ongoing benefit shows that we should kill and eat animals.

In fact, my view is that there are special considerations, arising from human rationality, that block the extension of the argument: human beings, including many severely mentally disabled human beings, have distinctive rights that animals lack, and this means that we cannot kill and eat enslaved human beings, 
not even for their own good. The rational activity that is in play is not merely a high state of consciousness but a self-reflective activity in which a creature reflectively assesses its own mental life, which it changes in accordance with that self-assessment. Rational activity is different in kind from consciousness (see Descartes [1985: 2: 288], where he grants sensations to animals, and Descartes [I985: I: 348 and 376-77], where he grants them passions).

I shall not and need not argue for a rationality view here and spell out the specific way that a rationality view invokes rational activity and delivers rights, or consider its scope of application (for example, encompassing severely mentally disabled human beings). There are two points that can be made. First, even if an argument of the sort pursued here were to yield an obligation to kill and eat enslaved human beings, it would only be what philosophers call a pro tanto obligation, and such an obligation might or might not be outweighed by the special rights of human beings. Second, a crucial empirical premise of the argument advanced here for killing and eating animals is that these kinds of animals would not exist were it not for the practice of killing and eating them. The parallel premise is not at all plausible for human beings. Even if, counterfactually, groups of human beings were enslaved and eaten, it would remain true that they could survive and flourish outside that practice. There are, of course, science-fiction scenarios (such as H. G. Wells's Time Machine) where such a practice is imagined as a norm, with different empirical premises. But that is fiction, and it is hard to know the rights and wrongs where we depart so much from actuality. At any rate, because of the empirical fact that no group of human beings actually depends for its existence on a meat-eating practice in which human beings are killed and eaten, it is very unlikely that there is even a pro tanto obligation to kill and eat enslaved human beings that needs to be outweighed. No group of human beings actually owes its existence to cannibalistic meat-eating practices in the way that billions of animals do owe their lives to carnivorous meat-eating practices. Therefore, we do not need to worry about the mere possibility too much, especially because it is also plausible that there are distinctive human rights in play that would protect human beings in that merely possible situation.

\section{Which Animals?}

One familiar objection to appealing to animal benefit is that it means that we have duties at a time to creatures who do not yet exist at that time, which would be odd. But this is not something that the historical benefit view is committed to, and such an objection would misunderstand the view presented here as a consequentialist one. We have duties to present existing animals, to eat them, in virtue of a past and present mutually beneficial relationship between human beings and animals of that kind, where animals 'of that kind' means animals that are the descendants of animals that have actually benefitted from the practice. (We would owe nothing to animals of the same species that have been casually isolated for a long time from those that have benefitted, but this is an unlikely scenario.) The present fact that these animals have a certain history is what imposes the obligation. True, many future animals that do not yet exist will benefit by our eating presently existing 
animals. But our duties are to present and actual animals, to eat them, not to future or merely possible animals that will benefit. The view is not a consequentialist one because the grounds of duties look backward to the past, not forward to the future. Our duties are to presently existing animals because the existing practice has benefitted animals in the past and continues to benefit them in the present, and that is why we should now eat the animals produced by the beneficial practice.

The duty to eat animals is like the duty to care for one's parents in their old age. The history of benefit matters. What our parents did for us in the past is a ground of our later duty to them. But direct consequentialism allows that it might be fine to bump off our parents regardless of what they have done for us. Moreover, the rationale for respecting our parents is not an indirect consequentialist one: what matters are not the future benefits of a general practice of caring for parents, but the actual history of a particular parent and child pair (see Zangwill 20II). In a similar way, farmers should kill and eat or allow others to kill and eat the animals they have cared for because of what the past and ongoing present practice has done for animals and also human beings. That history dictates a bond of loyalty between human beings and the animals they care for, a bond much like that between parents and children. Of course, it is not usual to eat our own parents, and in this respect I concede that the two cases are different. However, they are similar in that systematic historical benefit generates a bond of loyalty and duties of care. It is just that in the case of animals, caring entails killing, unlike in the case of one's parents.

All currently existing domesticated animals have benefitted from the carnivorous practice, and therefore human beings have a duty to each and every animal to see that it plays its allotted role in the beneficial practice. We have a duty to eat animals not just generally but to the particular animals that we eat when we eat them. And it is the history of systematic benefit that is the ground of the duty to the particular animal, not its current benefit or the benefit of its brethren. It is true that the act of killing and eating an animal does not benefit that animal at the point when we kill and eat it. However, at the very point of action, the relevant concept is justice, just as it is for human beings when they carry out punishment in a legal setting. In the Crito, Socrates argues that he has a duty to accept his punishment from the law of Athens given the past benefits that he has accepted from the city (even though the punishment is unjust). He would be acting unjustly if he avoided punishment. In the Gorgias, Socrates connects the justice and benefit in a surprising way when (at Gorgias $476 \mathrm{a}-48 \mathrm{I}$ b) Socrates expresses the surprising view that a person benefits from being punished (Plato I997). Likewise, someone might go as to far as to say that particular animals are benefitted when they are killed and eaten. But perhaps it is more natural to the contemporary ear to allow benefit and justice to come apart, so that due to the history of benefit, it is just that the animal should die even though it is not to its benefit at that point.

\section{Good and Good-For}

Since benefit to animals plays a crucial role in my argument, albeit not a consequentialist role, we can expect the objection that if something is good for 
sheep, there must be some specific sheep that it is good for. It cannot be good for the abstract type sheep. The reply is that the practice has been good for countless millions of sheep. These are actually existing, particular past sheep. But what about our continuing the practice in the present and in the future? Which sheep does that benefit? The future sheep that it will benefit do not yet exist, so how can the practice be good for them?

A related worry is presented by McMahan, namely, that animals that do not yet exist have no interest in being caused to exist (McMahan 2008: 6). It is true that once a particular animal exists, it then has an interest in continuing to exist and not being killed and eaten. As we saw, that is the point of view of a person who betrays others in the prisoner's dilemma. But that reply leaves unanswered McMahan's complaint that no animal has an interest in its own coming into existence. This argument threatens even the historical benefit argument, where actual and specific sheep are in question. Nevertheless, McMahan rightly concedes that it is good for an animal to be caused to exist (McMahan 2008: 6), but that is all that the argument requires once we step over the following metaphysical mistake about goodness.

To put the point simply: there can be good without good-for. Once something exists, then states of the world can affect properties of the thing and thus can be good or bad for it. But the good of existence is not of this sort. There are, as G. E. Moore thought, good states of the world; in that sense only are existence facts good in relation to something (Moore I903). We can distinguish 'existence good' and 'property good'. Some existence facts are intrinsic goods. For example, the existence of a newborn healthy baby is not merely good for its parents or even for the baby; its existence is just intrinsically good, given that it has states of consciousness. (Whether there are nonexistence facts that are intrinsically good is doubtful.) That there are facts of existence that are intrinsic goods is highly plausible, and the theoretically driven attempt to deny this is deeply implausible. Indeed, it is plausible that existence good has priority over property good because of the metaphysical priority of existence over properties: properties must attach to something that exists. Therefore, skepticism about existence good without property good is implausible because there is no good-for without plain good. (This runs contrary to Korsgaard 20I8.)

The impact of this on our discussion is as follows. The existence of conscious happy sheep is good-a good state of the world. How could anyone deny that? It is no problem that there is nothing that the sheep's existence is good for. It is not only that there are no (other) conscious beings that it is good for; existence good is a certain kind of intrinsic good, and as such it does not have to be good for conscious beings or for anything. Perhaps, though, we might say that the existence of conscious happy sheep is 'good for the world'. Those who deny that there are existence goods are engaging in strange and unusual metaphysics, and they run counter to common sense. (Perhaps we might also say that existence is good for a conscious happy sheep, just as it seems that it is to my great good fortune that my mother and father met each other at teacher training college.)

In many cases, it is good that something is good for some creature, and that good (that something is good for the creature) is not good in a good-for way. It is an intrinsic good. Contrast this with a scenario where all the goods are goods-for. 
A goal in football might be good for a football fan who supports one team but not good for another football fan who supports the opposing team. But these goods are merely good-for because there is nothing good about the goal being scored or not being scored. Good-fors that are not backed by intrinsic goods are a flimsy basis indeed for the ethics of anything.

This view of the relation between 'good' and 'good for' has been denied. However, the good-for-centric view is not intuitive, and those who would use it to deny life to animals owe us a very good argument for the good-for view. Certainly, there is no non-question-begging argument from good-for against the historical benefit view defended here.

\section{Who is Obligated?}

On whom, exactly, does the duty to eat meat fall? I have said that it is our duty, where this means human beings whose forebears participated in the carnivorous practice. It is our collective duty. In principle, that means that if enough people eat enough meat to sustain the beneficial practice, then particular people's obligations might lapse or be weakened, just as a person's duty to help a stranger in trouble lapses or weakens if there are already enough other people helping the stranger. However, while it is good to help sustain a beneficial practice, that is not the main reason for eating meat; rather, the main reason is the historical one that the practice has been beneficial to participants. We eat the animals that have benefitted out of respect for the past-a matter of honor, if you like. This duty binds all of us although perhaps we need not eat much meat if others are bearing more of the weight of the duty. It is like carrying a coffin: one does it out of respect for the past, but if there are enough pallbearers, one need not volunteer.

At the time of death, the benefit that a particular sheep has reaped is in the past. Now is the time for this sheep to pay. But why does a particular person have a duty to exact that payment from this sheep? Consider the following analogy. Suppose someone commits a crime and therefore should be punished. Unless people have a special role in the law, perhaps as prison warders, they have no special duty to administer punishment. However, sometimes there is no such division of labor. There might be a shared responsibility for enforcement in some jurisdictions. Consider jurisdictions in which there is a 'duty of rescue' law. Suppose that someone is drowning or suffering a crime. Then a person nearby who is aware of the situation, a bystander, is under an obligation to the person drowning or suffering a crime. Eating meat is, in this respect, like the duty of rescue law: a person is duty-bound to the particular sheep being eaten.

Killing and eating animals seem to differ in this respect. The slaughtering of animals is done by specialists, and the reason for this is that they are probably more skilled in doing this so as to minimize suffering. Therefore, it is permissible to delegate this duty to them. There is no such reason for the duty to eat meat, which falls on all of us. But even in the case of slaughtering, we all have a duty to delegate the duty.

What if some people claim to be altogether exempt from the burden imposed by the carnivorous practice because they are vegans and do not participate in the 
practice? Perhaps their parents were vegans too. Nevertheless, every vegan has ancestors who were carnivores; indeed, their ancestors were in a meat-eating relationship with animals for thousands of years. A modern vegan is the beneficiary and inheritor of this ancient tradition, and is therefore duty-bound to it and to continue to nurture the animals that depend on that practice. If vegans do not continue the practice, they are selfish free riders, depending for their existence on their ancestors who ate meat. Almost all modern vegans would not exist if their ancestors had not eaten meat. Vegans depend for their existence on their forebears who virtuously benefitted animals and who reaped benefits themselves from the carnivorous practice. Therefore, vegans are individually bound by the same collective duty to eat meat as the rest of us.

History is relevant, but how much history? Quite a lot. Vegans deriving from a few generations of vegans are not absolved from duties imposed by thousands of years of participation in the mutual beneficial carnivorous practice that the vegans' ancestors also participated in. However, it should be conceded that members of an isolated culture that has a very long-standing vegan cultural tradition stretching back a thousand years would be absolved of the duty to kill and eat meat. Neither the present-day members of that culture nor their immediate forebears are part of a beneficial practice that confers duties on most other people. There might be people whose ancestors were not in a carnivorous symbiotic relationship with animals for the past thousand years. People from such a vegan culture who elect to eat meat would be virtuous, but doing so is not their duty. By contrast, a modern vegan who elects to opt out of the beneficial practice of their meat-eating forebears does wrong. Such vegans are selfish free riders who turn their back on their responsibilities to animals in general and to the particular animals that they fail to eat. (Hinduism and Buddhism are often wrongly thought to be predominantly vegan cultures, but there may be sects within these religious groups with very long-standing vegan traditions. If so, they are absolved from carnivorous duties although they would be virtuous if they were to eat meat.)

\section{Io. All Things Considered}

My argument has been that the historic and continuing benefit to animals of the practice of eating meat creates a duty to eat animals. Even so, this is not the only duty in the world. Of course. The duty is a pro tanto duty. It may be outweighed by other duties and obligations. But if it were not outweighed, it would amount to an all things considered or overall duty to eat animals.

What about the rights and wrongs of eating vegetables? Like nonconscious bacteria and earthworms, vegetables are in a different moral category from conscious animals. There is nothing it is like to be a carrot. For this reason, we are not under an obligation to participate in a practice that has promoted and continues to promote the flourishing of carrots by eating them as we are under an obligation to participate in a practice that has promoted and continues to promote the flourishing of conscious animals. Nevertheless, eating vegetables is not morally neutral because it bears on the fulfillment of our other obligations, such as our obligation to eat animals. One argument would be that since eating vegetables 
distracts us from our obligation to eat animals, in that respect eating vegetables is morally wrong. We should not blithely pass over the opportunity to participate in a practice that has benefitted conscious animals by eating them. If so, we should ideally have a diet entirely of meat, with no vegetables at all! However, there are reputed to be health benefits for human beings from eating vegetables. If so, then eating vegetables helps us fulfill our obligations, such as our obligations to eat animals. That would give us derivative moral obligations to eat vegetables.

In considering the overall moral status of meat eating, we should factor in a variety of other things, such as the positive and negative consequences of meat-eating practices. Perhaps there are harms to the environment caused by farting and burping cows and sheep. This might justify us in eating sheep instead of cows if sheep fart or burp less, or relevantly differently, from cows. However, even if New Zealand sheep farming does cause pollution, these effects should be balanced against the interests of sheep, and, of course, we should try to mitigate that damage while retaining the sheep rearing.

We should not dwell only on additional negative effects. There are other positive aspects to the practice of eating meat that reinforce the argument from the benefit to animals from the carnivorous practice. Many other kinds of considerations also favor eating meat. One is the gustatory pleasure of human beings when they eat meat. We should not ignore human pleasures in eating meat (see Lomasky 20I3). These provide reasons that should be counted. However, those pleasures do not have much weight compared with the duty arising from historic and present benefit to animals. The human pleasure in eating meat is a welcome part of a good practice.

Other kinds of considerations are aesthetic ones. There is the beauty of meat itself, celebrated in the erotic novel Le Boucher by Alina Reyes (Reyes I99I). There is also the beauty of the countryside where animals live-the beauty of the grassy fenced hills, punctuated by grazing animals, should not be discounted. This beauty depends on our eating meat. Of course, aesthetic considerations sometimes conflict with moral considerations, and then we have a dilemma. Fortunately, in the case of animals, beauty and goodness go hand in hand: aesthetic and moral considerations point in the same direction. Aesthetic considerations provide additional justification for eating meat although, as with human gustatory pleasure, aesthetic considerations do not have much weight when compared with our duty to participate in a beneficial meat-eating practice.

Effects on human welfare and rights need to be weighed carefully. The employment that the meat-eating practice provides for millions of human beings needs to be considered. There are also other additional effects, for example, on other animals-wild animals for example. The calculation will be complex, and it might turn up some surprising results. Nevertheless, considered in itself, the meat-eating practice is clearly good, very good. Thus, it generates a very strong pro tanto reason for human beings to participate in it. Many factors need to be considered in arriving at an all-things-considered judgment of the value of participating in the practice of eating meat. However, we should not assume that these extraneous weighable factors are systematically negative. In many discussions, authors do not merely accentuate the negative, but they eliminate the 
positive (see Doggett 2018, for an example). This bias has all the hallmarks of conspiracy-theory reasoning. No one has ever made a convincing case that the overall effects of the meat industry or at least of the nicer (non-factory) parts of it, are negative. The overall assessment would have to be holistic, and it would have to be complex, with numerous interacting factors. We have no reason to believe that the world would be better off if human beings did not eat meat. Those who think they know this are deceiving themselves.

There might be other good consequences of eating meat that we have not considered here. There might also be other positive or negative moral considerations that are not a matter of benefits or harms. However, as far as the practice of eating meat itself is concerned, it is clear that it is good to eat meat, we ought to eat meat, and eating meat is our duty.

\section{I. Coda}

Some people do not eat meat. It could be that they put their own self-interest before morality. Perhaps they do not like the taste, for example, or have some irrational taboo against it, just as irrational racial prejudice leads some people not to care about certain kinds of people or to harm them. Or it could be that they do not care about the welfare of conscious animals because speciesism leads them not to value a tradition that benefits those animals, in particular, speciesism causes them to ignore animals' pleasures and happiness. Whatever the psychological explanation, their practice is immoral. Eating meat is good, it is what we ought to do and our duty, and not to do so is bad and wrong. Where duty is in tension with self-interest, we should strive to put self-interest to one side and do our duty. Those happiness-deniers and life-deniers who have speciesist prejudices that prevent them from eating meat should strive to rid themselves of prejudice and do the right thing and eat meat.

Eating meat is creating life. It brings into existence beings with valuable states of consciousness. Or at least eating meat is an essential part of a practice whereby valuable conscious lives have been and are being created. (Recall that the argument is restricted to animals that have good lives overall, rather than including miserable factory-farmed animals.) This is as great a benefit as one can confer on creatures-so excellent an act is eating animals! Did not our parents give us a great gift, if not the greatest gift-life, existence? In a similar way, New Zealand sheep farmers who raise sheep kindly and kill them, minimizing distress, to make room for new generations of happy sheep are great benefactors of animal kind. They give life and happiness. Those who eat that meat should be proud to be part of such an excellent beneficial practice. Eating meat is an act of kindness. Eating meat is primarily about life, not death, and it should be celebrated as such.

NICK ZANGWILL 


\section{References}

Benetar, David. (2006) Better Not To Have Been. Oxford: Oxford University Press.

Callicott, Baird. (2016) 'The Environmental Omnivore's Dilemma'. In Ben Bramble and Bob Fisher (eds.), The Moral Complexities of Eating Meat (Oxford: Oxford University Press): 48-64.

Descartes, Rene. (1985) The Philosophical Writings of Descartes. Vols. I and 2. Edited and translated from the original Latin and French by J. Cottingham, R. Stoothoff, and D. Murdoch. Cambridge: Cambridge University Press.

Doggett, Tyler. (2018) 'Moral Vegetarianism'. Stanford Encyclopaedia of Philosophy. https://plato. stanford.edu/entries/vegetarianism/.

Korsgaard, Christine. (2018) Fellow Creatures: Our Obligations to the Other Animals. Oxford: Oxford University Press.

Lomasky, Loren. (20I3) 'Is it Wrong to Eat Animals?'. Social Philosophy and Policy, 30, I-20.

Mackie, John. (1977) Ethics: Inventing Right and Wrong. Harmonsworth: Penguin.

Marino, Lori. (2017) 'Thinking Chickens: A Review of Cognition, Emotion, and Behavior in the Domestic Chicken'. Animal Cognition, 20, I27-47.

McMahan, Jeff. (2008) 'Eating Animals the Nice Way'. Daedalus, I-I I.

Moore, G. E. ( 1903 ) Principia Ethica. Cambridge: Cambridge University Press.

Plato. (1997) Plato's Complete Works. Edited by John Cooper. Indianapolis: Hackett.

Regan, Tom. (1983) The Case for Animal Rights. Lost Angeles: University of California Press.

Reyes, Alina. (I99I) Le Boucher. Translated by David Watson. London: Methuen. Originally published in French in 1988.

Schmidz, David. (2008) Person, Polity, Planet. Oxford: Oxford University Press.

Scruton, Roger. (2000) Animal Right and Wrongs. $3 \mathrm{~d}$ ed. London: Continuum.

Singer, Peter. (1975) Animal Liberation. New York: Harper Collins.

Singer, Peter. (I979) 'Killing Humans and Killing Animals'. Reprinted in Unsanctifying Human Life (Oxford: Blackwell, 2005).

Stephen, Leslie. (1896) Social Rights and Duties. London: Library of Alexandria.

Zangwill, Nick. (20I I) 'Cordelia and Indirect Consequentialism'. Oxford Studies in Normative Ethics, I, $145-65$.

Zangwill, Nick. (20I8) 'Insane Consequentialism'. Utilitas, 30, 3 I7-32. 